\title{
Inhalt der 15. Lieferung
}

Sonderpolizeien (Fortsetzung). Von Oberregierungsrat Dr. Georg Müller, Essen . 628 Soziale Gerichtshilfe

Soziale Umwelt. Von Dr. Alexander Elster, Berlin . . . . . . . . . . . 636 Spermaflecke s. Biologische Untersuchungsmethoden.

Spionage und Landesverrat s. Volksverrat.

Sport. Von Dr. Alexander Elster, Berlin. . . . . . . . . . . . . . . . 640

Spuren und Spurensicherung. Von Dr. Hans Schneickert, Berlin . . . . . . 643

Staatspolizei. Von Justizrat Dr. Karl Friedrichs, Ilmenau . . . . . . . . . 646

Stadt und Land.

A. Kriminalsoziologie. Von Privatdozent Dr. Willy Gierlichs, Köln . . . . 654

B. Tatorts-Kriminalität. Von Referendar Dr. Hans Hermann Burchardt, Berlin . . . . . . . . . . . . . . . . . 663

Steckbrief. Von Reichsgerichtsrat Dr. h. c. Fritz Hartung, Leipzig . . . . . . 675

Sterilisation. Von Prof. Dr. Arthur Hübner $t$, Bonn, durchgesehen von Gerichtsmedizinalrat Prof. Dr. Vikt or Müller-HeB, Berlin . . . . . . . . 676

Strafanstalt s. Gefängnisbau und Strafvollzug.

Strafkolonieen s. Deportation.

StrafmaB s. Strafzumessung.

StrafprozeB s. Voruntersuchung, Verteidigung, StrafmaB, Strafzumessung, Strafprozessuales Schnellverfahren, Untersuchungshaft, Zeugenaussagen.

Strafprozessuales Schnellverfahren. Von Generalstaatsanwalt i. e. R. Dr. Karl Haf ner, Karlsruhe .....................

Strafregister. Von Amtsgerichtsrat Dr. Erich Kelz (beschäftigt im Reichsjustizministerium), Berlin ....................

Straftilgung. Von Amtsgerichtsrat Dr. Erich Kelz (beschäftigt im Reichsjustizministerium), Berlin.................... 690

Straf volizug.

A. Strafvollzug als Rechtsangelegenheit. Von Landgerichtsdirektor Dr. Hans Eichler (beschäftigt im Reichsjustizministerium), Berlin . . . . . .

B. Strafvollzug als Verwaltungsangelegenheit. Von Strafanstaltsoberdirektor Hans Ellger, Köln .....................

C. Strafvollzug als Erziehungsangelegenheit. Von Strafanstaltsoberdirektor Pfarrer Wilhelm Bleidt, Wittlich .............. 712

D. Strafvollzugsstatistik. Von Regierungsrat Dr. Ernst Roesner, Berlin . . 715 